\title{
Proactive effects of stimuli, delays, and response position during delayed matching from sample
}

\author{
SAMUEL L. MOISE, JR. \\ Environmental Neurobiology Laboratory \\ University of California at Los Angeles, Los Angeles, California 90024
}

\begin{abstract}
Effects of sample stimulus, delay, and correct response position from Trial $\mathrm{N}-1$ on performance during Trial $\mathbf{N}$ were examined for a two-choice delayed matching from sample task. The results seemed to demonstrate proactive interference with retention of sample stimuli on Trial $\mathrm{N}$ when that stimulus was different from Trial $\mathrm{N}-1$ as compared to when the stimulus was the same as on Trial $\mathrm{N}-1$. In addition, when stimuli were the same on Trial $N-1$ and Trial $N$, and Trial $N-1$ was incorrect, there was greater interference than if Trial $\mathbf{N}-1$ was correct. Evaluation of performance as a function of delays on Trial $\mathrm{N}-1$ and Trial $\mathrm{N}$ provided some support for D'Amato's recent description of delayed matching from sample performance as a temporal discrimination process.
\end{abstract}

Several experiments in recent years have revealed functional similarities between short-term memory in monkeys and man (see Jarrard \& Moise, 1971; D'Amato, 1973). In particular, retroactive interference effects have been shown to be as important determinants of memory task performance in monkeys as in man. The role of proactive interference factors has been more difficult to assess. Because of the considerable theoretical importance of proactive interference for the development of theories of memory in man, it is important to investigate for those who wish to construct theories of memory in animals.

In animal research, the evidence for proactive interference during short-term memory has been contradictory. Some relevant studies have manipulated length of intertrial interval where longer sepatation between trials presumably reduces the interference from events of the previous trial. Gleitman, Wilson, Herman, and Rescorla (1963) reported superior performance in a delayed response task under conditions of distributed practice ( 2 trials per day) as compared with a massed condition of 20 trials per day. On the other hand, Fletcher and Davis (1965) found no difference in delayed response performance when they tested monkeys at 8,16 , and 24-sec intertrial intervals. Jarrard \& Moise (1971), using the delayed matching to sample task, reported better performance of stumptail macaques with longer intertrial intervals $(15,30$, and $60 \mathrm{sec})$ than with a short interval $(5 \mathrm{sec})$. In humans also, longer intertrial intervals have reportedly led to increased performance (Decker \& Allen, Reference Note 1).

In a delayed matching from sample task with red and green stimuli, Jarvick, Goldfarb, and Carley (1969) presented negative stimuli (color different from the sample) before presentation of the sample. They found

This research was supported in part by U. S. P. H. S. Grant GM-16058 and in part by the Air Force Office of Scientific Research of the Office of Aerospace Research under Contract F44620-70-C-0017. Computing assistance was obtained from the Health Sciences Computing Facility, UCLA, sponsored by N. I. H. Grant RR-3. significant interference with performance when the negative stimulus preceded the sample by less than $8 \mathrm{sec}$. The interference effects were larger after $12-\mathrm{sec}$ retention intervals than after $1-\mathrm{sec}$ retention intervals. For the delayed response task in which position is the stimulus attribute to be remembered, Fletcher, Garske, Barron, and Grogg (1968) concluded that, for their rhesus monkeys, intertrial interference was the consequence, not the cause, of within-trial factors such as forgetting or inattention. Etkin and D'Amato (1969), in an examination of sample set size and differential experience with stimuli, and D'Amato (1971), in an extension of the differential experience investigation, found no significant effects due to sample set size or to differential experience. D'Amato concluded that their data, while not definitive, implicated factors other than proactive interference as determinants of performance in delayed matching tasks.

The present paper examines the effects of stimuli, delay, and response position from Trial $\mathrm{N}-1$ on performance in Trial $\mathrm{N}$ for a typical delayed matching from sample task (two stimuli, two choices). The presence of proactive interference due to competing memory traces from prior stimuli should be revealed by inferior performance when correct (sample) stimuli are different on Trial $\mathrm{N}-1$ and Trial $\mathrm{N}$ than when the stimuli are the same. In the former case the memory trace from the stimulus on Trial $\mathrm{N}-1$ should interfere with retention of the trace on the current trial, all other factors being equal.

An analysis of trial to trial effects of delays should permit a simple test of the temporal discrimination hypothesis of short-term memory proposed by D'Amato (1973). This hypothesis views short-term memory as a discriminative process in which the major discriminative cues are temporal. Using delayed matching from sample as an illustration, D'Amato suggests that the task at the time of matching is to decide which of the choice stimuli appeared as the sample most recently. This decision 
Table 1

Mean Percentage Correct as a Function of Delays on Trial $N-1$ and Delays on Trial $N$

\begin{tabular}{cllcc}
\hline \multirow{2}{*}{$\begin{array}{c}\text { Trial N } \\
\text { Delay }\end{array}$} & \multicolumn{4}{c}{ Trial N - 1 Delay } \\
\cline { 2 - 5 } & \multicolumn{1}{c}{5} & \multicolumn{1}{c}{5} & \multicolumn{1}{c}{10} & 20 \\
\hline 1 & $82.0^{*}$ & $72.9^{*}$ & $79.5^{*}$ & $78.4^{*}$ \\
5 & $65.1^{*}$ & $65.0^{*}$ & $67.4^{*}$ & $70.1^{*}$ \\
10 & 54.2 & 52.6 & $53.3^{*}$ & $66.1^{*}$ \\
20 & 51.1 & 42.3 & 48.7 & $58.8^{2}$ \\
\hline
\end{tabular}

*Significantly different from chance $(p<.05)$.

becomes more difficult with longer delays because the time since each stimulus was last seen as a sample becomes more similar. Performance is expected to be better when Trial $\mathrm{N}$ is preceded by a long delay Trial $\mathbf{N}-1$, as compared to a short delay Trial $\mathbf{N}-1$, since the difference in time since each stimulus was last seen as the sample is greater in the former than in the latter.

\section{METHOD}

\section{Subjects}

Four naive female Macaca nemestrina monkeys served as subjects. All animals had been implanted with chronic indwelling electrodes for subsequent EEG recording. These electrodes were not observed to affect the animals' behavior or performance as compared to nonimplanted animals who were similarly trained. Throughout training and testing these animals were maintained at $80-90 \%$ of their preexperimental ad-lib weight. Testing was performed in the morning with a supplementary feeding in the late afternoon.

\section{Apparatus}

During training and testing, each animal was restrained in her cage by a plastic collar. The animal in her cage was placed in a wooden test chamber so that she faced an aluminum test panel which contained three circular display holes (windows) arranged in a triangle with the apex toward the top of the box. Behind each circular opening was mounted a linear one-plane digital readout projection unit (Industrial Electronic Engineers). In front of the readouts were translucent plastic response switches mounted in the panel. Below the stimulus and response openings was a plastic food cup connected to a dispenser which delivered $180-\mathrm{mg}$ food pellets. Randomization, selection and presentation of stimuli and rewards, as well as recording of responses (including latencies) was performed by a PDP-8I computer interfaced with the behavioral test chamber. The arrangement was similar to that described by Moise and Jarrard (1969).

\section{Procedure}

In order to insure that the subjects' matching performance reflected control by the sample stimulus and not by extraneous cues, care was taken to properly balance presentation of stimuli, response position, and sequencing of trials with respect to stimulus and delay patterns (D'Amato \& O'Neill, 1971).

The subjects were trained to perform delayed matching from sample over a three-month period, following the procedure described by Moise and Jarrard (1969). During all training and testing, the animals were given 100 trials per day.

The subjects were first trained to press an illuminated window. This was followed by red-green discriminations with the correct stimulus being reversed each day. When the animals were performing at $90 \%$ correct responses on two consecutive days matching to sample was introduced. The first phase utilized a single sample stimulus (red or green color) each day with reversals of the correct stimulus on subsequent days. When $80 \%$ correct was attained, the sample stimulus was randomly chosen on each trial and performance continued until $80 \%$ correct was again achieved. This was followed by delayed matching from sample at delays up to 1 sec.

The delayed matching procedure was as follows. After pressing the sample stimulus (red or green light) that appeared at the apex of the triangle, the sample terminated and a delay began. The delay was followed by onset of two match stimuli (one red and one green) that appeared at the base of the triangle. The animal was required to match the sample with the correct stimulus by pressing one of the two windows. Each correct response was rewarded immediately with a $180-\mathrm{mg}$ reward pellet. Each incorrect response or failure to respond (not pressing the lighted sample or match within $10 \mathrm{sec}$ ) terminated the trial. Intertrial intervals were 15 sec.

When $80 \%$ correct performance was achieved at $1-\sec$ delay, random presentation of $0-, 1-, 5-, 10-$, and 20-sec delays was begun and 10 days of data was collected for the present analysis. Less than $1 \%$ of the trials were lost as a result of subjects failing to respond.

\section{Data Analyses}

Overall performance was assessed in terms of the usual function of delay interval. Proactive effects were analyzed with the use of a modified version of a general technique for examination of sequences of data (Nirenberg, Haber, \& Moise, 1973). This technique allows examination of any event given the presence of any particular sequence of preceding events. For the present analysis only substrings including two trials (Trial $\mathrm{N}-1$ and $N$ ) were analyzed. If there are proactive effects they might be expected to have maximum influence on the trial which immediately follows.

The data were analyzed for the effects of Trial $\mathbf{N}-1$ on Trial $\mathrm{N}$ when (a) the correct response position remained the same or changed, (b) when the correct stimulus remained the same or changed, and (c) as a function of delays.

\section{RESULTS AND DISCUSSION}

Overall mean percent correct for all animals showed a typical decrease in performance over delays (analysis of variance $\mathrm{F}=86.0, \mathrm{df}=4 / 12, \mathrm{p}<.001$ ). The values were $84.4 \%, 80.1 \%, 66.2 \%, 59.4 \%$, and $52.3 \%$ correct for delays of $0,1,5,10$, and $20 \mathrm{sec}$, respectively. Matching performance was adequately but not strongly developed in these animals as evidenced by the percent correct at $0 \mathrm{sec}$ delay $(84.4 \%)$. Performance at all delays except $20 \mathrm{sec}$ was above chance (Ts $>2.7, \mathrm{df}=3$, ps $<.05$, onetailed test). Latencies on incorrect responses were slightly longer than on correct responses $(2101 \mathrm{msec}$ and 2035 msec, respectively) and latency increased monotonically with length of delay $(F=5.9, \mathrm{df}=4 / 12$, $\mathrm{p}<.007)$. Although the animals were "beginners" in this task, there were no statistically significant trends toward improved performance over the 10 days of this experiment and the data were collapsed over days for further analysis.

\section{Change of Correct Response Position}

Figure 1 plots the effect of same position vs. change in position as a function of delay. Both points at $20-\mathrm{sec}$ 


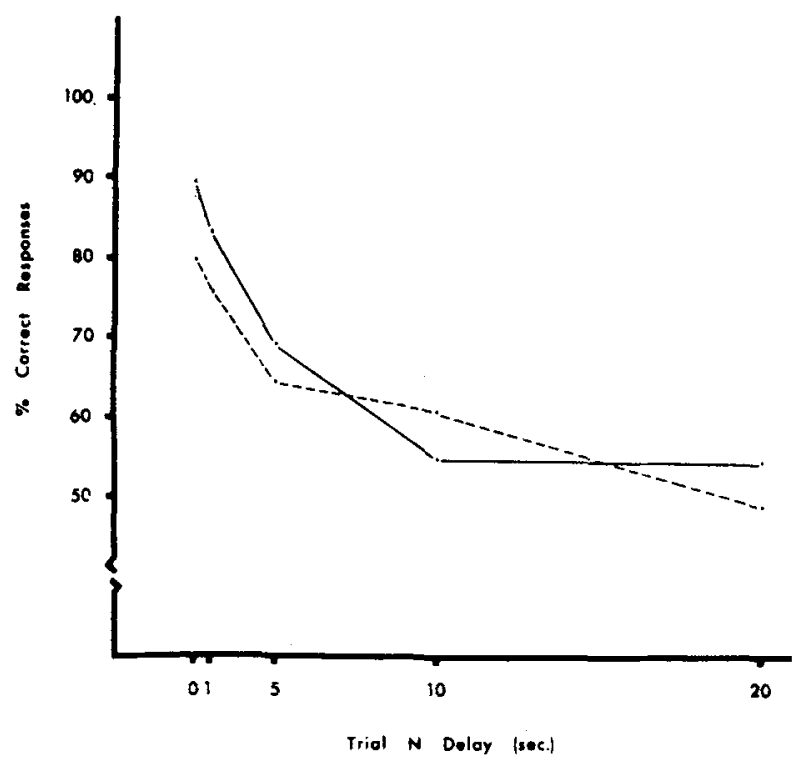

Figure 1. Percent correct Trial N responses when the correct match position is the same as the correct position on Trial $\mathbf{N}-1$ ( - ) and when the correct match position is different from the correct position on Trial $\mathrm{N}-1(----)$.

delay and the point for the same position curve (solid line) at $10-\mathrm{sec}$ delay did not differ from chance. The main effect due to change in correct response position was significant $(\mathrm{F}=15.15, \mathrm{df}=1 / 3, \mathrm{p}<.03)$. The interaction of response position with trial $\mathrm{N}$ delay was also significant $(F=3.32, \mathrm{df}=4 / 12, \mathrm{p}<.05)$. A significant performance difference between same and different response positions existed at 0 -sec delay ( $t$ test, $p<.05$ ) but not longer delays. Whatever interference is produced by a change in response position has minimal effect on memory function during Trial $\mathrm{N}$ since there are no statistical differences for delays longer than $0 \mathrm{sec}$

\section{Change of Sample Stimulus}

If the memory trace from sample stimuli on Trial N - 1 interferes with or facilitates retention of the sample stimulus on Trial $\mathrm{N}$, trials on which sample stimuli remain the same should show higher performance than trials on which sample stimuli have changed. As seen in Figure 2, performance was clearly higher when stimuli remained the same $(F=13.18, \mathrm{df}=1 / 3$, $\mathrm{p}<$.036). All points, except when sample stimuli changed (dotted line) at 20 -sec delay, are significantly above chance ( $\mathrm{ps}<.05$, one-tailed test). There was no interaction of performance with delay on Trial $\mathrm{N}$ $(\mathrm{p}>3)$.

It seems reasonable to assume that the outcome of Trial N - 1 (reward or no reward) must affect the strength of the memory trace for the sample on that trial and, therefore, the proactive effect of that trace on Trial $\mathrm{N}$ performance. If Trial $\mathrm{N}-1$ is rewarded, the memory trace for that sample stimulus might be "strengthened." If nonrewarded, that trace might be "weakened," or at least not strengthened. Higher performance can, therefore, be predicted on trials in which sample stimuli are the same, and Trial $\mathrm{N}-1$ is correct (SC) as compared to trials in which the stimuli are the same but Trial $\mathbf{N}-1$ is incorrect (SI). Further, performance can be expected to be higher when stimuli are different and Trial $\mathrm{N}-1$ is incorrect (DI) compared to when Trial $\mathrm{N}-1$ is correct (DC). In the latter case, the "wrong" stimulus on Trial $\mathrm{N}$ was strengthened by the reward on Trial $\mathbf{N}-1$. The data verified these predictions with $\mathrm{SC}=75.3 \%, \mathrm{SI}=64.5 \%, \mathrm{DC}=62.3 \%$, and $\mathrm{DI}=71.4 \%$. The statistical difference between $\mathrm{SC}$ and $\mathrm{SI}$ was $\mathrm{p}<.014$ and between DC and DI was $\mathrm{p}<.029$ in the predicted direction (Mann-Whitney $U$, one-tailed test). No differences in these relationships were demonstrated as a function of Trial $\mathrm{N}$ delay.

Whatever its source, interference from Trial N - 1 memory traces might be expected to produce differences in response latencies on Trial $\mathrm{N}$. When Trial $\mathrm{N}-1$ is correct, correct Trial $\mathrm{N}$ response latencies when sample stimuli remain the same should be shorter than when sample stimuli change. Correct responses following a change in sample stimuli imply that the animal somehow overcomes the disruptive effect of the stimulus change, which presumably takes additional processing time. As expected, mean latencies were shorter when sample stimuli were the same $(1965 \mathrm{msec})$ than when sample stimuli changed (2014 msec), but this difference was not significant. In general, none of the Trial $\mathrm{N}-1$, Trial $\mathrm{N}$ comparisons between latencies were significant. It would appear that more precise control over the animal's responses would be necessary to examine effects of proactive interference on latency.

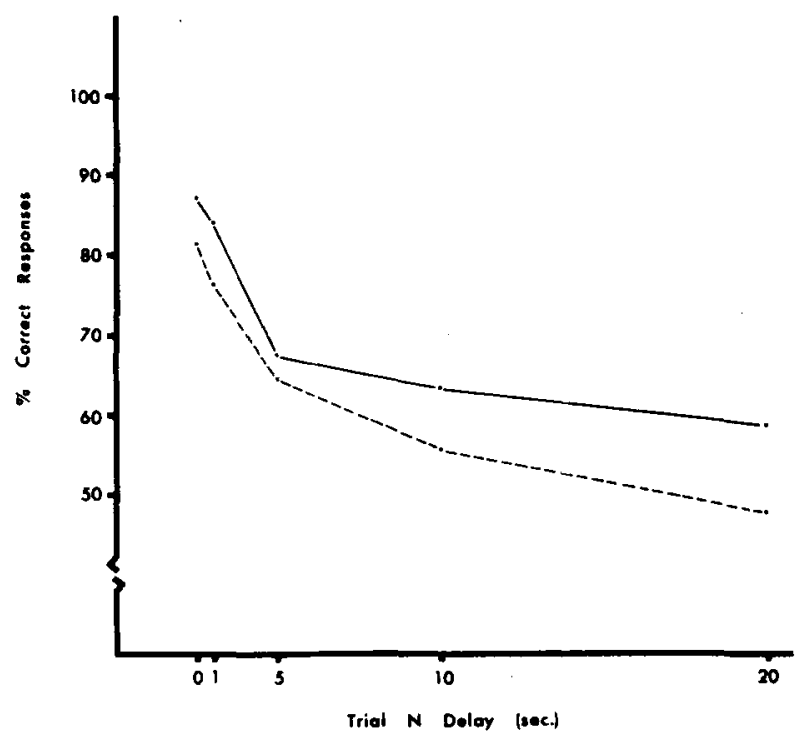

Figure 2. Percent correct Trial $\mathrm{N}$ responses when the sample stimulus is the same as the sample on Trial $\mathbf{N}-1$ ( and when the sample stimulus is different from the sample on Trial N - 1 ( - - - ) 
Another interpretation of these data is that subjects adopted a response strategy whereby they attempted to remember and respond to the last pressed match stimulus. A win-stay, loss-shift pattern would appear, and the relationship observed in Figure 2 would be expected. In this case, the DMS task would seem to need an unlikely reinterpretation since this would imply that the animals are remembering the stimulus responded to on Trial $\mathrm{N}-1$ as the basis for making their response on Trial $\mathrm{N}$. The Trial $\mathrm{N}$ sample stimulus would act to interfere with or facilitate retention of the Trial $N-1$ responded-to-stimulus in a retroactive manner. Examination of the data showed that the above chance performance of all the animals at nearly all delays was only possible if they relied on the sample from Trial $\mathrm{N}$ as the basis for making match responses.

\section{Effects of Delays on Performances}

Above chance scores were obtained for all Trial N . Trial $N-1$ delay combinations with two exceptions. Performance on $20-\sec$ Trial $\mathrm{N}$ delays was not significantly different from chance except when the delay on Trial $\mathrm{N}-1$ was $0 \sec (\mathrm{t}$ test, $\mathrm{p}<.05)$. Performance on 10 -sec Trial $\mathbf{N}$ delays was above chance only for 0 - and 20-sec Trial $\mathrm{N}-1$ delays.

Since 0 -sec delays are a control condition which may be subject to interference phenomena but do not involve memory in the same sense that longer delays do, a comparison of nonzero delay conditions was made in the light of D'Amato's temporal discrimination hypothesis of delayed matching from sample performance (see Table 1). Performance on Trial N, preceded by a short delay on Trial $\mathrm{N}-1$ should be inferior to performance preceded by a long delay on Trial N - 1 (D'Amato, 1973). In the former, the time-since-last-seen of each sample stimulus is more similar (i.e., less discriminable) than in the latter.

For short $(1 \mathrm{sec})$ trial $\mathrm{N}$ delays, the hypothesis is not supported. In this case, best performance followed 1 -sec delays with next best performance after 10-sec delays. For 5-sec Trial N delays, the trend supports D'Amato's hypothesis with best performance at 20-sec and next best at 10-sec Trial $\mathrm{N}-1$ delays. The highest scores for the 10-sec Trial $\mathrm{N}$ delay were at $20 \mathrm{sec}$ Trial $\mathrm{N}-1$ delay, all other Trial $\mathrm{N}-1$ values being at chance levels. Although no values were above chance for $20-\mathrm{sec}$ Trial $\mathrm{N}$ delays, the longest Trial $\mathrm{N}-1$ delay $(20 \mathrm{sec})$ produced higher performance than the other delays.

D'Amato suggests that the outcome (reward or nonreward) of Trial $\mathrm{N}-1$ might affect the discriminability of the time-since-last-seen intervals.
If incorrect Trial $\mathrm{N}-1$ responses make the discrimination of time-since-last-seen for the sample easier, higher performance should follow incorrect Trial $\mathrm{N}-1$ responses than correct Trial $\mathrm{N}-1$ responses. The present data revealed a nonsignificant trend in this direction.

As D'Amato points out, the actual situation is bound to be far more complex than the present analysis indicates. Better trained animals working at longer delays may be necessary for more rigorous evaluation. Clearly, further research is necessary to verify or disprove the hypothesis, but one of its main advantages is its formulation in terms amenable to disproof.

\section{REFERENCE NOTES}

1. Decker, L. H., \& Allen, C. K. The intertrial interval and proactive inhibition in short-term memory. Paper presented at the meeting of the Rocky Mountain Psychological Association, Albuquerque, N. M., May, 1969.

\section{REFERENCES}

D'Amato, M. R. Sample familiarity and delayed matching in monkeys. Psychonomic Science, 1971, 25, 179-180

D'Amato, M. R. Delayed matching and short-term memory in monkeys. In G. H. Bower (Ed.), The psychology of learning and motivation: Advances in research and theory. New York, Academic Press, 1973, vol. 7, pp. 227-269.

D'Amato, M. R., \& O'Neill, W. Effect of delay-interval illumination on matching behavior in the capuchin monkey. Journal of the Experimental Analysis of Behavior, 1971, 15, 327-333.

Etkin, M., \& D'Amato, M. R. Delayed matching-to-sample and short-term memory in the capuchin monkey. Journal of Comparative and Physiological Psychology, 1969, 69, 544-549.

Fletcher, H. J., \& Davis, J. K. Evidence supporting an intratrial interpretation of delayed response performance of monkeys. Perceptual and Motor Skills, 1965, 21, 735-742.

Fletcher, H. J., Garske, J. P.. Barron, T., \& Grogg, T. M. Intertrial and intratrial determinants of delayed responses of monkeys. Journal of Comparative and Physiological Psychology, 1968, 65, 66-71.

Gleitman, H., Wilson, W. A., Herman, M., \& Rescorla, R. A. Massing and within-delay as factors in delayed-response performance. Journal of Comparative and Physiological Psy chology, 1963, 56, 445-451.

Jarrard, L. E., \& Moise, S. L. Short-term memory in the monkey. In L. E. Jarrard (Ed.), Cognitive processes of nonhuman primates. New York: Academic Press, 1971, pp. 3-24.

Jarvick, M. E., Goldfarb, T. L., \& Carley, J. L. Influence of interference on delayed matching in monkeys. Journal of Experimental Psychology, 1969, 81, 1-6.

Moise, S. L., \& Jarrard, L. E. A computer-controlled system for training and testing primates. Behevior Research Methods \& Instrumentation, 1969, 1, 234-236.

Nirenbirg, L. M., Haber, J., \& Moise, S. L., Jr. A high speed algorithm for computing conditional probabilities of substrings of sequentially observed data. Behavior Research Methods \& Instrumentation, 1973, 5, 291-294.

(Received for publication May 2, 1974. Revision accepted June $18,1975$. 